\begin{tabular}{|l|l|l|l|l} 
Hung out to dry & $\begin{array}{l}\text { Gene therapy } \\
\text { Still no European } \\
\text { money for biology } \\
\text { infrastructure } \\
p 723\end{array}$
\end{tabular}

\title{
Relations thaw between genome rivals as finish line draws near
}

Paul Smaglik, Washington

The war of words that has marked - many would say marred - progress towards sequencing the human genome seems to have reached a cease-fire. The move comes as both the publicly funded Human Genome Project (HGP) and its commercial rival, Celera Genomics of Rockville, Maryland, prepare to announce within the next few weeks that they have separately sequenced and assembled versions of the human genome.

The détente was orchestrated at a cancer conference at the National Institutes of Health in Bethesda, Maryland, last week. It comes months after negotiations between the two broke amid a bitter exchange of accusations (see Nature 404, 117; 2000).

Consecutive speeches by Francis Collins, director of the National Center for Human Genome Research and leader of the public project, and Craig Venter, head of Celera, rekindled speculation that the projects may yet cooperate - or at least share the credit.

"There's no reason for there to be wars," said Venter, after Collins had reiterated that the projects are "complementary". Each praised the other's approach, where before they had pointed out perceived weaknesses.

But hints of the old chill slipped through. Collins mentioned repeatedly the benefits of the HGP releasing its information every 24 hours - a sticking point that has prevented

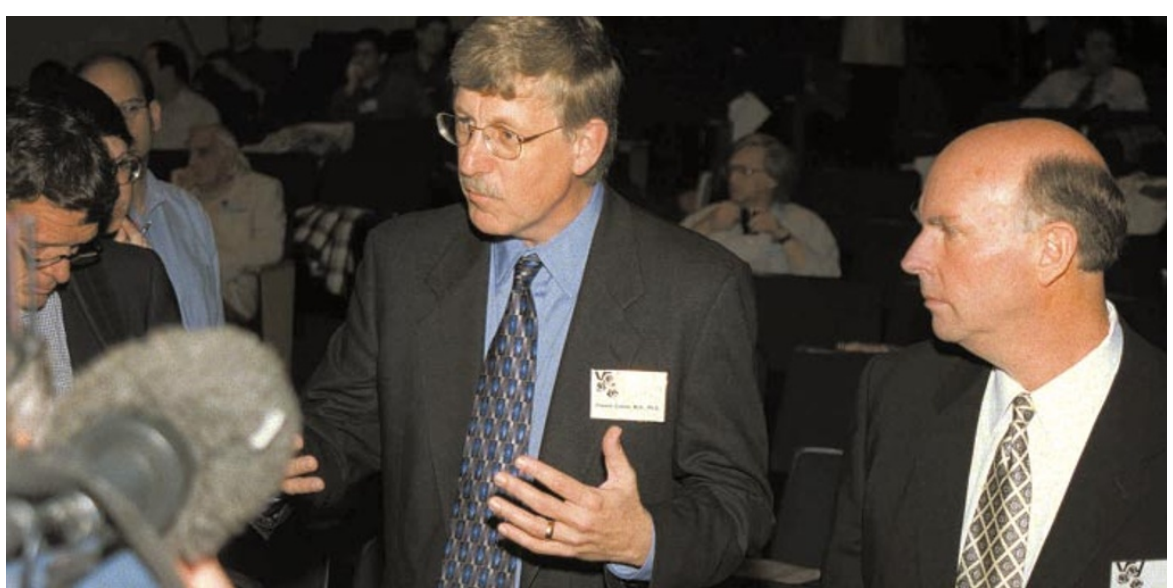

Jaw not war: in recent speeches, Collins (left) and Venter praised each other's approaches.

closer cooperation between the two projects. And Venter noted wryly that Collins' chronology of genomic milestones neglected to mention Haemophilus influenzae - the first bacterial genome, sequenced under Venter's leadership at The Institute for Genomic Research, in Rockville, Maryland.

In general, however, the tone was one of mutual praise. Collins, for example, lauded Venter's use of 'whole-genome shotgun' sequencing - in contrast to his earlier expressions of scepticism about its effectiveness for large genomes.

Shotgun sequencing involves breaking the genome into millions of fragments, read-

\section{China warned of AIDS 'disaster'}

One of China's leading AIDS researchers warned last week that, if the country does not move to combat the disease, it could soon face a "national disaster", with the largest number of AIDS cases in the world.

According to the China News Agency, Zeng Yi, the director of the Institute of Demographical Research at the University of Beijing, told a meeting of the Chinese Academy of Sciences that AIDS threatened all the gains made since the country's economic reforms and opening up to the
West. But, he said, China has dragged its feet in its efforts to control the accelerating spread of HIV infection.

Zeng added that, among other things, there was a lack of investment in scientific research, and that the attitude of some officials was hampering prevention work. He told the academy that one researcher had been fired because local officials believed that, by revealing the AIDS situation in their region, he had made them look bad and hurt the region's image. ing their ends, and then using computers to assemble them. Celera used the technique, along with gene maps built by Gerry Rubin, of the University of California at Berkeley, to assemble the fruitfly genome.

Collins is considering doing the same for the public project's version of the mouse genome. "We'velearned a lot from Dr Venter and others about the quality of the wholegenome shotgun," he said.

Venter, in turn, seemed grateful for the public project's contribution to his work. One version of Celera's human genome will incorporate the HGP's data. "More data in any assembly will add more quality to the project," said Venter.

His remarks contrasted with previous criticism that the HGP's 'working draft' of the human sequence would probably contain too many 'holes'. In April, for example, Venter told a Congressional hearing that the HGP "may be at a stage where quality and scientific standards are sacrificed for credit".

Venter also applauded Collins' recent decision to sequence the mouse - which Celera is already about a third of the way through — and rat genomes.

James Watson, director of Cold Spring Harbor Laboratory, who has criticized Celera's plans to keep its information proprietary, noted that Celera had spurred the public project on. "From the public viewpoint, everyone has gained," he said. 